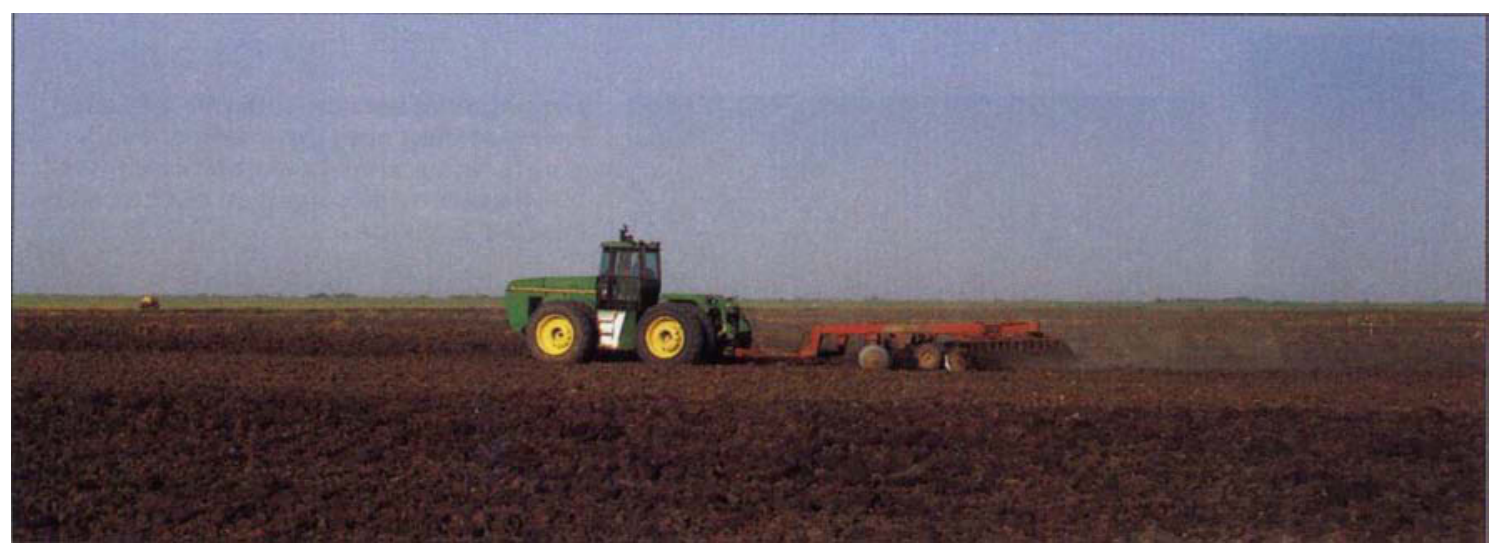

\title{
Overinflated tractor tires waste fuel, reduce productivity
}

\author{
Kleber P. Lancas
}

\author{
Shrini K. Upadhyaya
}

\author{
Muluneh Sime
}

tion will grow, leading to severe oscillation. In an effort to solve this problem, engineers have found that power hop can be controlled if radial ply tires are operated at much lower pressures, which are chosen based on axle load. This pressure level is referred to as "low/correct pressure." Working closely with tire manufacturers, engineers at tractor manufacturing companies developed a new set of guidelines to select low/ correct pressures for radial ply tractor tires. Use of these low/ correct pressures turns out to be beneficial not only in controlling powerhop, but also for higher tractive (implement-pulling ability) and fuel efficiencies, enhanced productivity and a reduction in the extent of soil compaction. This win-win situation has led to considerable interest nationwide in the use of low/ correct pressures for radial ply tractor tires.

The objective of this study was to quantify the benefits of employing low/correct pressures on radial ply tractor tires under typical California farming conditions.

\section{Field experiments}

We conducted two tests during the spring and summer of 1994, using a $350 \mathrm{hp} \mathrm{John} \mathrm{Deere} \mathrm{8870,} \mathrm{4WD} \mathrm{tractor,}$ which was equipped with $20.8 \mathrm{R} 48$ duals on both front and rear axles. Tests were conducted in the spring in Woodland, in a relatively wet Capay
Sayedahmad Shafii

clay soil. The summer tests were conducted on the Russell ranch in Davis, in a field with dry, Rincon silt clay/ Yolo silt loam soil. This field had been stubble-disked following a winter wheat crop. Field operations considered during this study were stubble disking in the spring and subsoiling with a mounted subsoiler in the summer.

Spring tests examined two different soil conditions (tilled and untilled) and two tractor tire-inflation pressures. We selected four rice checks of about 13 acres each. Two checks were disked, using a finishing disk, to create tilled conditions. One of these tilled checks, and one untilled check, then were randomly assigned to a high inflation pressure of $24 \mathrm{psi}$. The remaining checks were assigned low / correct pressure treatments of $13 \mathrm{psi}$ in front axle tires and 11 psi in rear axle tires. Checks assigned the low/ correct pressure treatment were disked using an 18-foot Kewanee stubble disk. Fuel consumption in each check was measured using a simple fuel gauge designed for this study. Initial fuel level was noted by parking the tractor in a specific location before a test. After the test, the tractor was parked in the same location and refueled to the initial level. Fuel consumption was determined as the amount of fuel necessary to refill. Productivity was determined by measuring the time it took to disk 

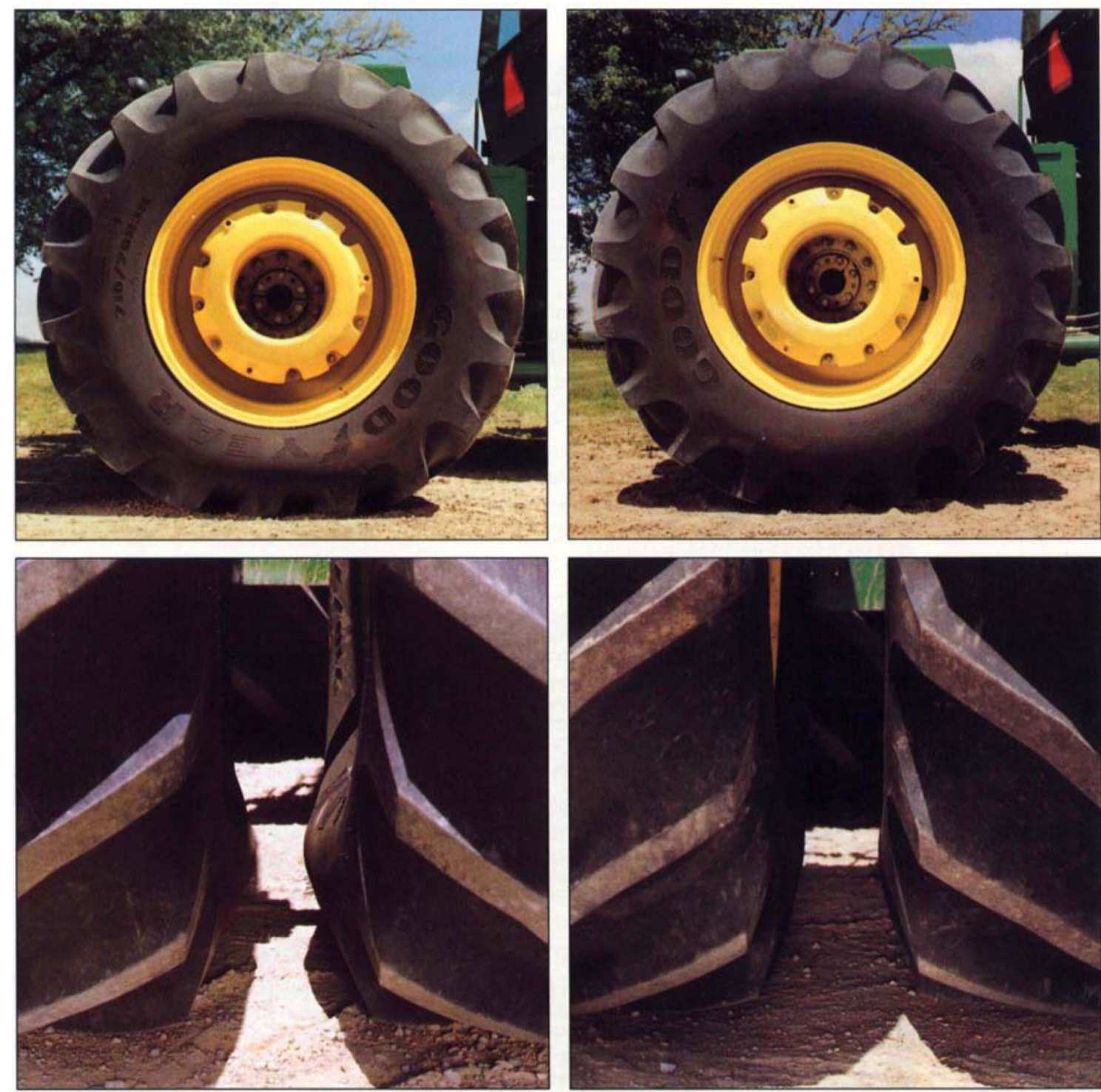

tent, and texture. $\mathrm{Al}$ though no direct relationship exists between compactness and cone index, it is often used as a relative indicator of soil compaction. Cone index values were replicated 10 times in each check. In addition, eight cone index values were measured in the tire track and six in the undisturbed area in the vicinity of tire tracks (fig. 1). Instantaneous values of slip, forward speed and engine rpm were measured using a performance monitor installed in the tractor cab.

The summer tests were conducted with a mounted, 9-shank John Deere subsoiler using two inflation pressure levels of 24 psi and low/ correct pressure (13 psi on the front axle and 14 psi on the rear axle). The field was divided into two blocks, which were

Use of low/correct tire pressure (top and lower left) controls power-hop and improves implement-pulling ability and fuel efficiencies, while enhancing productivity and reducing soil compaction. Overinflated tires shown In top and lower right.

1,000 feet along a straight line; we measured this 10 times in each check.

To determine soil moisture content and bulk density, we obtained five soil samples from each check using a volumetric core ring. A hydraulically operated standard cone penetrometer was used to obtain cone index values. The standard cone penetrometer is a cone with a base diameter of 0.798 inches and an apex angle of 30 degrees (ASAE Standard S313.2), which is mounted on a 0.625 -inch rod and pushed into the soil at the rate of 72 inches per minute. The force required to push this probe through the soil divided by the base area of 0.5 square inches is known as the cone index.
This is essentially a measure of how hard or compact the soil is with depth. Cone index is a composite soil parameter that depends on soil density (measure of soil compaction), moisture con-

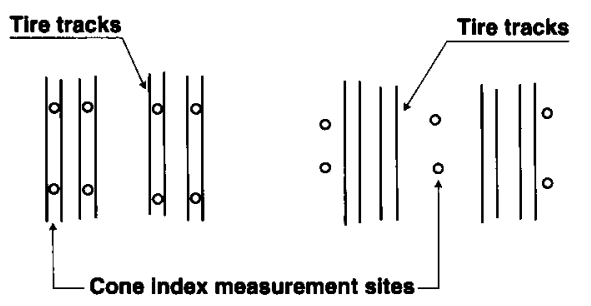

A. On track (8 replications) B. Off track (6 replications)

Fig. 1. Cone index measurement sites. further subdivided into two 1,500 foot-by-250-foot plots. These plots were randomly assigned an inflation pressure level. The test procedure was similar to that employed in the spring. Experimental data consisted of fuel consumption, time to travel 1,000 feet during the field operation, moisture content, bulk density, cone index data (under the track and adjacent to the track in the undisturbed area), and tractor performance data such as slip, forward speed and engine rpm.

\section{Selection of low/correct pressure}

Since the spring tests were conducted with a towed disk harrow, the static weight distribution of the properly ballasted tractor was necessary to determine the low/correct pressure. 
This information can be obtained from the tractor dealer. For our tractor, weight distribution was 21,030 pounds on the front axle and 18,330 pounds on the rear axle. Load per tire on the front axle was $5,257.5$ pounds and $4,582.5$ pounds on the rear axle. The correct inflation pressures for 20.8R42 tires used as duals were 13 psi in front axle tires and $11 \mathrm{psi}$ in rear axle tires.

The summer tests were conducted with a mounted subsoiler. When a mounted implement is used, the rear axle must be weighed with the implement in raised position because tire wear during transport on paved roads becomes the limiting condition for tractors with mounted implements. This weight can be determined easily with the help of a truck scale. In our case, the rear axle weight was 22,690 pounds. Note that the front axle is weighed with the implement lowered or detached, which is the same as the static weight. This weight can be obtained from the tractor dealer or by weighing with the implement lowered. The load per tire and correct inflation pressure for tires on the rear axle, in our case, were $5,672.5$ pounds and $14 \mathrm{psi}$, respectively. Front tire pressure was $13 \mathrm{psi}$, as in the spring tests.

\section{Fuel savings, higher productivity}

The soil at both test locations was quite moist in spring (average of $37.2 \%$ on dry basis) and relatively dry in summer (average of $10.2 \%$ on dry basis) (table 1). The specific gravity of the soil in the rice checks was lower than that of summer plots because the clay soil swelled considerably at high moisture content.

Tables 2 and 3 list mean values of fuel consumption rate, productivity, cone index values under the tire tracks (on-track) and adjacent to the tire tracks (off-track), and engine performance data (instantaneous engine $\mathrm{rpm}$, forward speed and wheel slip). These data indicate that using low / correct tire pressure reduced fuel consumption, increased productivity (ac/hour), and led to higher forward speed and lower slip values in all three cases - tilled and untilled dur-
TABLE 1. Soil moisture content and density (specific gravity) results in test plots, 1994

\begin{tabular}{|c|c|c|c|c|}
\hline Test & Soil conditions & Tire pressure & Moisture content & Specific gravity \\
\hline & & psi & $\%$ & \\
\hline \multirow{5}{*}{$\begin{array}{l}\text { Spring, } \\
1994\end{array}$} & Firm (untilled) & 24 & 37.7 & 1.22 \\
\hline & & $13 / 11^{*}$ & 39.3 & 1.20 \\
\hline & Tilled (just below & 24 & 38.3 & 1.22 \\
\hline & the tilled layer) & $13 / 11^{*}$ & 33.4 & 1.21 \\
\hline & Average & & 37.2 & 1.21 \\
\hline \multirow{5}{*}{$\begin{array}{l}\text { Summer, } \\
1994\end{array}$} & Block 1/ Tilled & 24 & 9.6 & 1.50 \\
\hline & & $13 / 14 t$ & 9.9 & 1.66 \\
\hline & Block 2/Tilled & 24 & 11.8 & 1.65 \\
\hline & & $13 / 14 \dagger$ & 9.5 & 1.59 \\
\hline & Average & & 10.2 & 1.60 \\
\hline
\end{tabular}

-13 psi in front tires, 11 psi in rear tires.

$\dagger 13$ psi in front tires, 14 psi in rear tires.

TABLE 2. Effects of high inflation pressure and low/correct pressure on productivity, soil compaction and engine performance, spring 1994

\begin{tabular}{lcccccccc}
\hline \hline $\begin{array}{l}\text { Soil } \\
\text { condi- } \\
\text { tions }\end{array}$ & $\begin{array}{c}\text { Tire } \\
\text { pressure }\end{array}$ & $\begin{array}{c}\text { Fuel } \\
\text { consumption } \\
\text { per area }\end{array}$ & $\begin{array}{c}\text { Area } \\
\text { covered } \\
\text { per hour }\end{array}$ & $\begin{array}{c}\text { Off-track } \\
\text { cone } \\
\text { index }\end{array}$ & $\begin{array}{c}\text { On-track } \\
\text { cone } \\
\text { index }\end{array}$ & $\begin{array}{c}\text { Instant. } \\
\text { engine } \\
\text { rpm }\end{array}$ & $\begin{array}{c}\text { Instant. } \\
\text { forward } \\
\text { speed }\end{array}$ & $\begin{array}{c}\text { Instant. } \\
\text { wheel } \\
\text { slip }\end{array}$ \\
\hline & psi & gal/ac & acre/hour & psi & psi & rpm & mph & $\%$ \\
Untilled & 24 & 1.75 & 12.24 & 117.0 & 163.2 & 2,026 & 5.6 & 10.8 \\
& $13 / 11^{*}$ & 1.43 & 13.16 & 101.7 & 117.3 & 2,137 & 6.0 & 7.1 \\
Tilled & 24 & 1.35 & 11.72 & 128.5 & 134.6 & 2,176 & 5.4 & 5.9 \\
& $13 / 11^{*}$ & 1.08 & 12.39 & 126.0 & 130.2 & 2,225 & 5.9 & 1.3 \\
\hline
\end{tabular}

$\cdot 13$ psi in front tires, 11 psi in rear tires.

TABLE 3. Effects of high inflation pressure and low/correct pressure on productivity, soil compaction and engine performance, summer 1994

\begin{tabular}{|c|c|c|c|c|c|c|c|c|}
\hline $\begin{array}{l}\text { Repli- } \\
\text { cation }\end{array}$ & $\begin{array}{c}\text { Tire } \\
\text { pressure }\end{array}$ & $\begin{array}{c}\text { Fuel } \\
\text { consumption } \\
\text { per area }\end{array}$ & $\begin{array}{c}\text { Area } \\
\text { covered } \\
\text { per hour }\end{array}$ & $\begin{array}{l}\text { Off-track } \\
\text { cone } \\
\text { index }\end{array}$ & $\begin{array}{l}\text { On-track } \\
\text { cone } \\
\text { index }\end{array}$ & $\begin{array}{c}\text { Instant. } \\
\text { engine } \\
\text { rpm }\end{array}$ & $\begin{array}{l}\text { Instant. } \\
\text { forward } \\
\text { speed }\end{array}$ & $\begin{array}{c}\text { Instant. } \\
\text { wheel } \\
\text { slip }\end{array}$ \\
\hline & psi & galac & acre/hour & psi & psi & $r p m$ & $m p h$ & $\%$ \\
\hline \multirow[t]{2}{*}{1} & 24 & 2.87 & 7.53 & 282.5 & 338.5 & 1956 & 4.5 & 11.9 \\
\hline & $13 / 14^{*}$ & 2.56 & 7.74 & 327.2 & 323.3 & 1954 & 4.5 & 8.2 \\
\hline \multirow[t]{2}{*}{2} & 24 & 2.76 & 7.20 & - & - & 1919 & 4.1 & 15.1 \\
\hline & $13 / 14^{*}$ & 2.74 & 7.67 & - & - & 1966 & 4.5 & 9.2 \\
\hline
\end{tabular}

$\bullet 13$ psi in front tires, 14 psi in rear tires.

TABLE 4. Savings in tractor fuel consumption and improvement in productivity due to correctly inflated radial ply tires

\begin{tabular}{|c|c|c|c|c|}
\hline \multirow[t]{2}{*}{ Soil and test conditions } & \multicolumn{2}{|c|}{ Savings in fuel consumption } & \multicolumn{2}{|c|}{ Improvement in productivity } \\
\hline & gal/ac & $\%$ & acre/hour & $\%$ \\
\hline $\begin{array}{l}\text { Stubble disking in an untilled } \\
\text { Capay clay soil, spring } 1994\end{array}$ & 0.32 & 18.3 & 0.92 & 7.5 \\
\hline $\begin{array}{l}\text { Stubble disking in a tilled } \\
\text { Capay clay soil, spring } 1994\end{array}$ & 0.27 & 20.0 & 0.67 & 5.7 \\
\hline $\begin{array}{l}\text { Subsoiling in a Rincon silt clay/ } \\
\text { Yolo silt loam soil, summer } 1994\end{array}$ & 0.17 & 6.0 & 0.34 & 4.6 \\
\hline
\end{tabular}




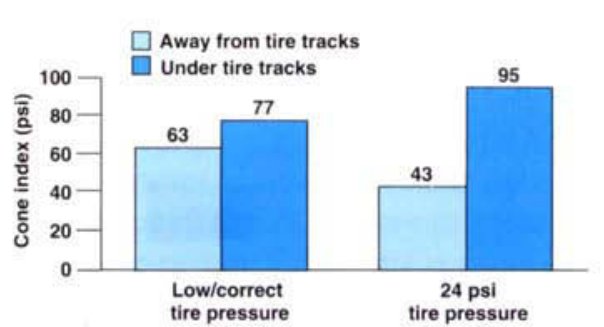

Fig. 2. Comparison of soil compaction (cone index values) for low/correct and high inflation pressure (24 psi) tires, in tilled layer, for the summer test.

ing the spring, and stubble-disked in the summer. The increase in productivity and forward speed, and the decrease in wheel slip go hand-in-hand since they are mathematically related.

Based on the savings in fuel consumption and enhancement in productivity (table 4), we estimated savings of $\$ 791 /$ section in tomato production, $\$ 468 /$ section in rice production, and $\$ 591 /$ section in cotton production. Total potential savings in California for production of these three crops was estimated at 2.3 million gallons of diesel fuel and 60,000 hours of labor. At $\$ 0.71$ per gallon of diesel fuel, savings in fuel and productivity were estimated at about $\$ 2$ million. These estimates were based on typical primary tillage operations employed in the production of these three crops.

\section{Soil compaction}

The differences in soil compaction levels depended on existing soil conditions during field tests. The extent of soil compaction - as measured by mean cone index values - increased in the untilled, moist Capay clay soil by $9.8 \%$ when low / correct pressure was employed and $70.3 \%$ when 24 psi inflation pressure was employed (tables 2 and 3 ). In the relatively dry, stubble-disked, Rincon silt clay/Yolo silt loam soil, soil compaction increased by $23.4 \%$ when low / correct pressure was employed and by $119.4 \%$ when 24 psi pressure was utilized. In the hard soil below the tilled layer, which was measured to a depth of 12 inches, there was almost no change in

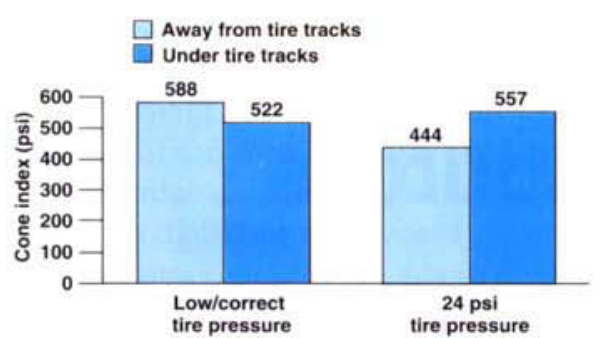

Fig. 3. Comparison of soil compaction (cone index values) for low/correct and high inflation pressure (24 psi) tires, in untilled layer, for the summer test.

cone index values with the low / correct pressure treatment. Plots that received 24 psi pressure treatment showed a $25 \%$ increase. Cone index values obtained in tilled and untilled layers during summer tests indicate using low/ correct pressure reduces the extent of soil compaction when compared to using high inflation pressure (figs. 2 and 3 ). In the tilled, wet Capay clay soil, changes in cone index values were similar for both pressure treatments in the upper tilled and the lower untilled layers (fig. 4). However, we believe these cone index values represent the resistance of large, wet clay lumps created by the previous disking operation. Under such conditions, it is very difficult, if not impossible, to get representative cone index data. It should also be noted that there was no incidence of power-hop during the spring or summer tests.

\section{Summary of benefits}

Our data was obtained by using a John Deere $8870,4 W D$ tractor equipped with $20.8 \mathrm{R} 42$ duals on both the front and rear axle. Based on our study, we found that use of low/correct pressure for radial ply tractor tires compared to a high inflation pressures of 24 psi led to the following:

1. The tractor consumed $18.3 \%$ less diesel fuel while its productivity increased by $7.5 \%$ when stubble disking in an undisturbed, moist (37.2\% moisture content on dry basis) Capay clay soil. The increase in mean cone index values in the tire tracks was higher at 24 psi pressure $(70.3 \%)$ than when low/correct pressure was used (only $9.8 \%)$.

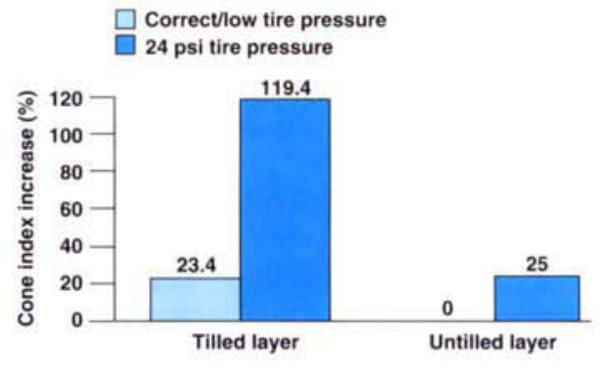

Fig. 4. Comparison of soil compaction (cone index values) increase, in percentage, for low/correct and high inflation pressure (24 psi) tires, in tilled and untilled layers, for the summer test.

2. In tilled, moist (37.2\% moisture content on dry basis) Capay clay soil, the tractor required $20 \%$ less diesel fuel and productivity increased $5.7 \%$ during the same stubble-disking operation. However, the changes in cone index values were about the same for both the high pressure and low/correct pressure treatments.

3 . Fuel savings were estimated at $6 \%$ and increase in productivity at $4.6 \%$ when the tractor was used for subsoiling previously stubble-disked, dry Rincon silt clay/Yolo silt loam plots with a mounted subsoiler. Mean increase in cone index values in tire tracks was $119.4 \%$ for high pressure treatments compared to $23.4 \%$ for low/correct pressure treatment.

K.P. Lancas is Visiting Scholar, S.K. Upadhyaya is Professor, M. Sime is Research Assistant, and S. Shafii is Visiting Scholar, Department of Biological and Agricultural Engineering, UC Davis.

The authors are grateful to the California Energy Commission for their financial support for this project. Moreover, we are indebted to Dr. Jack Wiley, Principal Engineer, Deere and Co., and Mr. Drew Shorter, Agricultural Tire Engineer, The Goodyear Tire and Rubber Co., for many valuable suggestions during the course of this project.

For additional information on how to determine low/correct tire inflation pressure, refer to a handbook entitled "How to get the most from radial ply tractor tires: A guide to select the correct inflation pressure." The handbook is available through the Biological and Agricultural Engineering Department, UC, Davis, CA 95616 , (916) 752-0102. 